\title{
Comparison Between Hyperextension and Neutral Positions for Vertebroplasty and Kyphoplasty: Which is Best for Osteoporotic Vertebral Compression Fractures?
}

This article was published in the following Dove Press journal:

Journal of Pain Research

\author{
Yan Ding ${ }^{1} *$ \\ Shengjie Dong',* \\ Jingjie Wang' \\ Jinpeng $\mathrm{Cui}^{2}$ \\ Zhilin Cao' \\ Shiqiao $\mathrm{Lv}^{\prime}$ \\ 'Department of Orthopaedics, \\ Yantaishan Hospital, Yantai 264000, \\ People's Republic of China; ${ }^{2}$ Clinical \\ Laboratory, Yantaishan Hospital, Yantai \\ 264000, People's Republic of China \\ *These authors contributed equally to \\ this work
}

Correspondence: Shiqiao Lv

Department of Orthopaedics, Yantaishan Hospital, No. 91 Jiefang Road, Yantai 264000, People's Republic of China

Tel +86-1300I6I2636

Email 68402128@qq.com
Purpose: This study aimed to compare the demographic features (including total cost), surgical effects, radiographic parameters, and complications of kyphoplasty (KP) and vertebroplasty (VP) in the hyperextension (HP) and neutral positions (NP) and to assess their efficacy and cost-effectiveness for treating single-level osteoporotic vertebral compression fractures (OVCF).

Patients and Methods: This was a retrospective analysis of 245 consecutive patients who underwent KP or VP from February 2018 to February 2019 with observation on postoperative day 2 and at the one-year follow-up. The first 122 patients (86 KP and 36 VP cases) were treated in the neutral position, and the remaining 123 in the hyperextension position (90 VP and $33 \mathrm{KP}$ cases). Back pain and impact on daily life were evaluated. Cobb's angle and the ratio of the anterior (AR) and middle vertebral (MR) bodies were the main radiographic parameters. The chi-square test, one-way analysis of variance (ANOVA), repeated measurement ANOVA, and post hoc tests (Bonferroni adjustments) were used for statistical analysis.

Results: There were no significant differences in the demographic features, operation time, or rate of re-fracture at the one-year follow-up among the groups. The rate of cement leakage was significantly lower in the HPVP group than in the NPKP group. The total cost was significantly lower in the VP groups than in the KP groups. At the one-year follow-up, back pain was significantly lower in the HPVP group than in the NPKP group. The Oswestry Disability Index, Cobb's angle, AR, and MR in the HPVP group were similar to those in the NPKP and HPKP groups, but better than those in the NPVP group.

Conclusion: HPVP can achieve better pain relief, and similar disability scores, Cobb's angle, AR and MR recovery, with a lower total cost, compared with NPKP. HPVP is the most economically efficacious treatment for OVCF.

Keywords: cement leakage, Cobb's angle, kyphosis, surgical outcome, vertebral height

\section{Introduction}

Osteoporotic vertebral compression fracture (OVCF) is a common consequence of osteoporosis. ${ }^{1}$ OVCF may result in acute or chronic pain, impaired mobility, height loss, spinal deformity, reduced pulmonary function, depression, osteoporosis progression, and even mortality. ${ }^{2-4}$ Although patients with mild symptoms can be treated with bed rest and analgesia, most patients cannot tolerate non-surgical treatment due to the additional complications related to immobilization. ${ }^{2}$ 
Minimally invasive surgery, including percutaneous vertebroplasty (VP) and kyphoplasty (KP), has been demonstrated to be safe and efficacious. ${ }^{5-8}$ Most importantly, it has also been proven effective in reducing the risk of mortality. ${ }^{9}$ Thus, in recent decades, it has become the firstline treatment for $\mathrm{OVCF}^{2,10,11}$

One of the main disadvantages of both KP and VP is that satisfactory restoration may not be obtained. Thus, surgeons have opted for various improved surgical techniques. A review of the literature revealed reports on the performance of $\mathrm{KP}$ or $\mathrm{VP}^{12,13}$ in the hyperextension position with satisfactory results. However, to our knowledge, no reports compared the surgical effects, radiographic parameters, and complications of KP in the hyperextension (HPKP) and neutral positions (NPKP), and of VP in the hyperextension (HPVP) and neutral positions (NPVP). The objective of this retrospective study was to determine the most efficacious and economical surgical procedure for OVCF.

\section{Methods}

\section{Setting}

We retrospectively reviewed the records of 245 consecutive patients who were diagnosed with OVCF and underwent KP or VP in our spine center from February 2018 to February 2019. All the patients were observed and assessed at admission, on postoperative day 2 (POD2) after mobilizing from the bed, and at one-year follow-up. The first 122 patients (86 NPKP and 36 NPVP cases) were treated in the neutral position. We then learned that surgery in the hyperextension position may be more beneficial to the patients, so the 123 subsequent patients (90 HPVP and 33 HPKP cases) were treated in this way. All patients underwent preoperative X-rays, computed tomography $(\mathrm{CT})$, and magnetic resonance imaging (MRI) to clarify the diagnosis and to assess the radiological parameters.

\section{Participants}

The criteria for inclusion in this study were as follows: 1) conformance with the criteria of the Chinese guidelines for the diagnosis and treatment of osteoporosis, namely the occurrence of a fragility fracture (vertebral fracture resulting from low-energy trauma, quantified by the World Health Organization as forces equivalent to a fall from a standing height or below), or a T-score of bone mineral density $(\mathrm{BMD}) \leq-2.5$ standard deviations (SD); ${ }^{14}-162$ ) single-level vertebral fracture; 3) fracture at the thoracolumbar region (T10-L2); and 4) disease duration of under three weeks. The exclusion criteria included the following: 1) infection, primary and metastatic spinal tumors, multiple myeloma; 2) neurological symptoms (any complaints of leg and/or perineal numbness and/or weakness); and 3) inability to undergo MRI to make a definite diagnosis of single-level OVCF. The study design was approved by the ethics board of Yantaishan Hospital (permit number 2020002), and consent to use the data and images was signed by each patient and their relatives.

\section{Variables and Data Measurement}

The demographic details (including age, gender, body mass index (BMI), duration from trauma to surgery, and total cost), operative information (including level of affected vertebrae, operation time, and injected cement volume), radiological data (including BMD, pre- and postoperative X-rays), and complications (including cement leakage and re-fracture) were collected and analyzed. The most severe overall back pain was assessed using the visual analog scale (VAS) score, and the impact on the patients' daily lives was evaluated by the Oswestry Disability Index (ODI). To eliminate individual differences, we compared the ratio of the anterior (AR, anterior height of vertebral body/posterior height of vertebral body on lateral X-ray photograph) and middle vertebral bodies (MR, middle height of vertebral body/posterior height of vertebral body on lateral X-ray photograph) instead of the absolute heights of the anterior and middle vertebral bodies. These two ratios and the vertebral Cobb's angle (taking the affected vertebrae as the center, the angle between the horizontal line of the upper vertebral body's upper-end plate, and the lower vertebral body's lower-end plate) were measured using lateral X-rays, and they were the main radiographic parameters for comparison. All the operations were performed by an experienced senior spinal surgeon. One junior doctor, blinded to the aim of the research, documented the demographic features, operative information, VAS and ODI scores, and complications. Two doctors, experienced in treating spinal disorders and blinded to the aim of the research, analyzed the aforementioned data in the preoperative period, on POD2 when the patient mobilized from bed, and at the one-year follow-up. The average value of their measurements was the final result, and if there was a marked difference (the two measurements of the Cobb's angle differed by $5^{\circ}$, or the AR and MR differed by $5 \%$ ), a more experienced senior 
doctor, also blinded to the research, remeasured the images to eliminate the error.

\section{Surgical Technique}

All patients were instructed to lie prostrate for approximately half an hour twice a day prior to the operation.

The surgical instruments for VP and the balloon for KP were purchased from Shanghai Kinetic Medical Co. Ltd. (Shanghai, China). The bone cement (Mendec Spine) was obtained from Tecres SPA (Sommacampagna VR, Italy).

To perform HPVP and HPKP ${ }^{13,17,18}$, the patient was first put in the prone position, with multiple pillows under the chest and ilium to suspend the abdomen. One solid paddle was placed under both thighs to maintain the whole body in the hyperextension position. Second, a G-arm X-ray machine (WHALE, Boston, USA) was positioned to take simultaneous anterior-posterior and lateral X-rays. Third, the operator gently pressed the back of the patient until the pain could no longer be tolerated. This was maintained for one minute to achieve maximum hyperextension. Fourth, after sterilization, local anesthesia $(0.5 \%$ lidocaine, Shandong Hualu Pharmaceutical Co. Ltd, Liaocheng, China) was applied via multipoint injections, including of the local muscle, fascia, and the articular capsule. Fifth, VP or KP was performed in the hyperextension position. In a systematic review by Yang et al, the bilateral approach was not found to be superior to the unilateral approach. ${ }^{19}$ Therefore, the unilateral transverse process-pedicle approach, which can reach the contralateral part of the vertebral body, was used. ${ }^{20-22}$ The injection process was monitored continuously under G-arm fluoroscopy. The procedure was stopped immediately if high resistance was encountered or if the bone cement came near to the posterior wall of the vertebral body. The amount of injected cement was noted. The patients were kept on bed rest for approximately six hours postprocedurally. A typical case is shown in Figure 1.

To perform NPVP or NPKP, the patient was placed in the prone position on a specially made silicon pad with a hole for the abdomen. No restoration maneuver was performed, and the unilateral transverse process-pedicle approach puncture and bone cement injection were applied under observation on the G-arm monitor. In KP, balloon dilation was performed before the bone cement injection.

\section{Statistical Methods}

Continuous variables, including age, BMI, BMD, duration, operation time, injected cement volume, total cost, VAS,
ODI, and radiographic parameters (Cobb's angle, AR and MR) are expressed as mean \pm standard deviation. Categorical variables, including gender, affected levels, cement leakage rate, and re-fracture rate, are expressed as frequencies and/or percentages. Chi-square tests were performed to compare gender, affected level, rate of cement leakage, and rate of re-fracture among the groups. One-way analysis of variance (ANOVA) was performed to compare age, BMI, BMD, duration of disease, operation time, injected bone cement, and total cost. After one-way ANOVA testing, post hoc tests (Bonferroni adjustments) were performed to obtain the pairwise comparison for injected bone cement and total cost among the four groups. Repeated measurement ANOVA tests were performed to compare VAS, ODI, Cobb's angle, AR and MR. After repeated measurement analyses, post hoc tests (Bonferroni adjustments) among the four groups were conducted at the same timepoint. SPSS (Version 25.0, IBM Corp., Armonk, NY, USA) was used for statistical analysis. The significance level was set at $P<0.05$.

\section{Results}

The correlation data conformed to a normal distribution according to Levene's test. The demographic and operative information of the different groups, and comparison values among the groups, are shown in Table 1. There were no significant differences in the mean age, gender composition, BMI, BMD, duration of disease, affected levels, operation time, and rate of re-fracture at the one-year follow-up among the groups.

The volumes of injected bone cement were $6.02 \pm$ $0.85 \mathrm{~mL}, 6.53 \pm 0.96 \mathrm{~mL}, 7.43 \pm 0.89 \mathrm{~mL}$, and $7.69 \pm$ $0.75 \mathrm{~mL}$ in the NPVP, NPKP, HPVP, and HPKP groups, respectively. The volume of the injected bone cement in the HPVP group was significantly lower than that in the HPKP group $(P<0.05)$, but similar to that in the NPVP and NPKP groups $(P>0.05)$. The rate of cement leakage was $33.33 \%(11 / 33)$ in the HPKP group, which was significantly lower than the $62.79 \%(54 / 86)$ in the NPVP group $(P<0.01)$ and the $54.44 \%(49 / 90)$ in the HPVP group $(P<0.05)$, but not significantly different from the $55.56 \%(20 / 36)$ in the NPKP group $(P>0.05)$. There was no significant difference when comparing NPVP to NPKP, NPVP to HPVP, or NPKP to HPVP $(P>0.05)$. No neurological deficit or pulmonary embolism occurred in these four groups.

The total cost of the procedure was $¥ 29,110.20 \pm$ 1764.64 and $¥ 29,508.56 \pm 1555.68$ in the NPVP and 

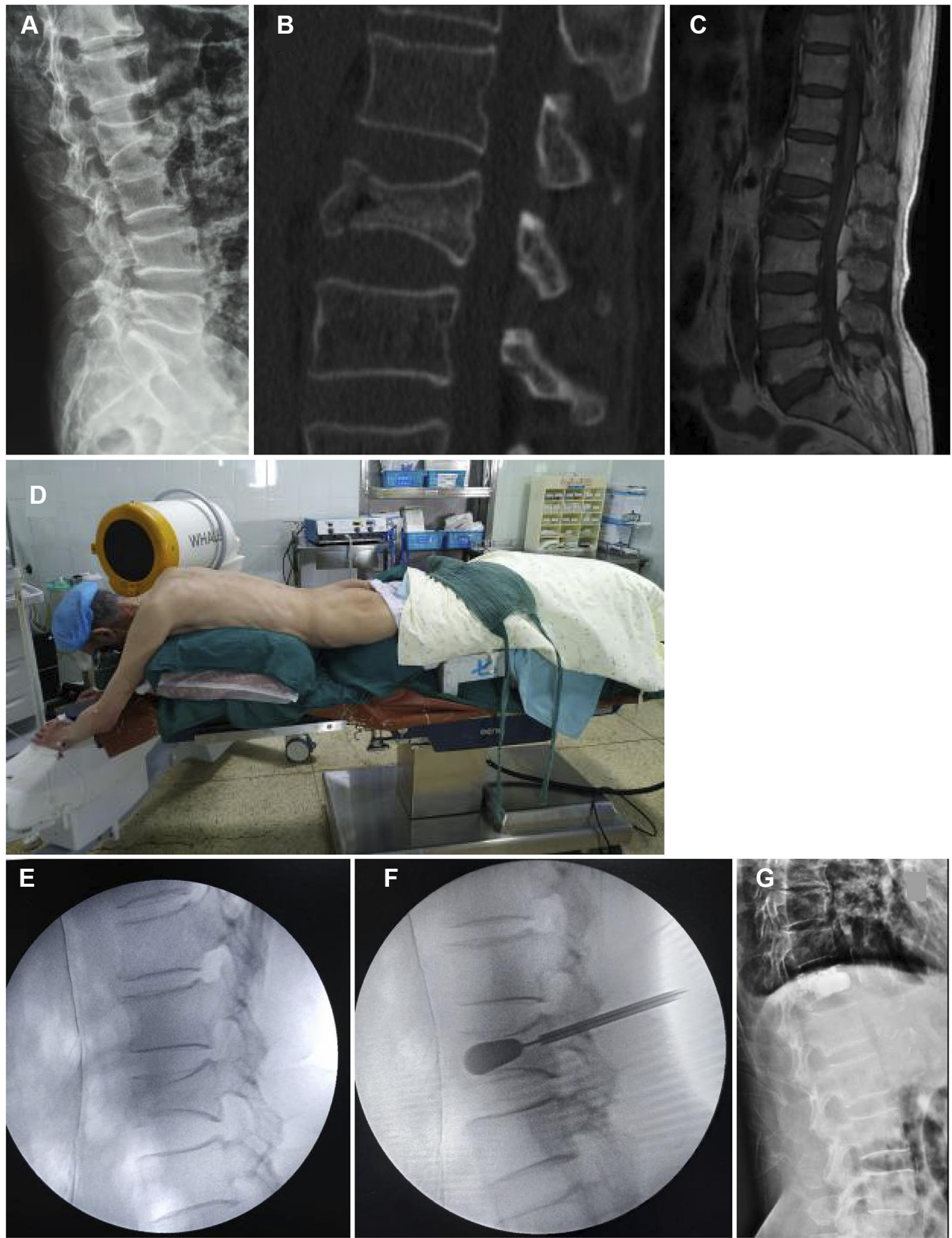

Figure I Typical case. An 8I-year-old man experienced back pain for 18 days, especially when changing position, caused by falling and buttocks hitting the ground. The patient was neurologically intact. (A) Preoperative X-ray (lateral). (B) Neutral position preoperative computed tomography. The affected vertebrae showed a fracture, and the trabeculae of the other vertebra were sparse. (C) TI-weighted image of preoperative magnetic resonance imaging. The intravertebral cleft sign can be seen. (D) Hyperextension position at surgery. (E) Lateral X-ray after placement in hyperextension position. Anterior vertebral height recovery and Cobb's angle reduction can be noted. (F) Lateral X-ray after balloon inflation. Endplate and middle vertebral height recovery can be seen. (G) Postoperative X-ray (lateral). 
Table I The Demographic, Operative Information Statistical Values, and P-values of Different Groups

\begin{tabular}{|c|c|c|c|c|c|c|}
\hline Variables & NPVP & NPKP & HPVP & HPKР & $\mathbf{T} / \chi^{2} / \mathbf{F}$ & $\mathbf{P}$ \\
\hline Number & 86 & 36 & 90 & 33 & & \\
\hline $\begin{array}{l}\text { Age (years) } \\
\text { Mean } \pm S D\end{array}$ & $68.50 \pm 7.78$ & $68.81 \pm 7.80$ & $71.71 \pm 9.41$ & $69.33 \pm 9.11$ & 2.330 & 0.075 \\
\hline $\begin{array}{l}\text { Gender } \\
\text { Male } \\
\text { Female }\end{array}$ & $\begin{array}{l}18 \\
68\end{array}$ & $\begin{array}{l}10 \\
26\end{array}$ & $\begin{array}{l}23 \\
67\end{array}$ & $\begin{array}{l}14 \\
19\end{array}$ & 5.733 & 0.125 \\
\hline BMI $\left(\mathrm{kg} / \mathrm{m}^{2}\right)$ Mean $\pm S D$ & $24.73 \pm 2.94$ & $25.4 I \pm 2.98$ & $24.49 \pm 2.98$ & $23.68 \pm 2.55$ & 2.145 & 0.095 \\
\hline $\begin{array}{l}\text { BMD } \\
\text { Mean } \pm S D\end{array}$ & $-2.83 \pm 0.78$ & $-2.98 \pm 0.80$ & $-3.03 \pm 0.76$ & $-2.67 \pm 0.78$ & 2.131 & 0.097 \\
\hline Duration (days) Mean $\pm S D$ & $8.67 \pm 5.68$ & $8.83 \pm 6.27$ & $9.94 \pm 5.71$ & $7.18 \pm 4.43$ & 2.093 & 0.102 \\
\hline $\begin{array}{l}\text { Affected level } \\
\text { TI0 } \\
\text { TII } \\
\text { TI2 } \\
\text { LI } \\
\text { L2 }\end{array}$ & $\begin{array}{l}3 \\
12 \\
26 \\
29 \\
16\end{array}$ & $\begin{array}{l}0 \\
6 \\
12 \\
13 \\
5\end{array}$ & $\begin{array}{l}3 \\
13 \\
31 \\
27 \\
16\end{array}$ & $\begin{array}{l}0 \\
5 \\
4 \\
15 \\
9\end{array}$ & 10.264 & 0.593 \\
\hline $\begin{array}{l}\text { Operation time }(\min ) \\
\text { Mean } \pm S D\end{array}$ & $24.14 \pm 3.84$ & $24.44 \pm 2.90$ & $24.64 \pm 3.17$ & $24.18 \pm 2.72$ & 0.340 & 0.796 \\
\hline $\begin{array}{l}\text { Injected cement volume }(\mathrm{mL}) \text { Mean } \\
\pm \mathrm{SD}\end{array}$ & $6.02 \pm 0.85$ & $6.53 \pm 0.96$ & $7.43 \pm 0.89$ & $7.69 \pm 0.75$ & 51.820 & $0.000 * *$ \\
\hline Cement leakage (\%) & $54(62.79 \%)$ & $20(55.56 \%)$ & $49(54.44 \%)$ & II (33.33\%) & 8.365 & $0.039 *$ \\
\hline Re-fracture (\%) & I(I.16\%) & $0(0 \%)$ & $I(I . I I \%)$ & $I(3.03 \%)$ & 1.348 & 0.718 \\
\hline Total Cost (Chinese Yuan) Mean \pm SD & $\begin{array}{l}29,110.20 \\
\pm 1764.64\end{array}$ & $\begin{array}{l}44,428.94 \\
\pm 3477.45\end{array}$ & $\begin{array}{l}29,508.56 \\
\pm 1555.68\end{array}$ & $\begin{array}{l}44,584.58 \\
\pm 3296.54\end{array}$ & 734.810 & $0.000 * *$ \\
\hline
\end{tabular}

Notes: $* P<0.05, * * p<0.01$.

Abbreviations: BMI, body mass index; BMD, bone mineral density; NPVP, vertebroplasty in neutral position; NPKP, kyphoplasty in neutral position; HPVP, vertebroplasty in hyperextension position; HPKP, kyphoplasty in hyperextension position; SD, standard deviation.

HPVP groups, respectively (no significant difference). However, the costs were significantly higher $(P<0.01)$ in the NPKP (Y44,428.94 \pm 3477.45) and HPKP ( $¥ 44,584.58 \pm 3296.54$ ) groups, although the costs in these two groups were not significantly different. The trends of the aforementioned three parameters are shown in Figure 2.

The changing trends, exact value, and comparison by repeated measurements of VAS, ODI, and radiographic parameters (Cobb's angle, AR, and MR) of the four groups are shown in Figure 3 and Table 2. For the VAS score, the values in the neutral position (both the NPVP and NPKP groups) at POD2 were significantly lower than that preoperatively $(P<$ $0.01)$ but similar to that at the one-year follow-up $(P>0.05)$, while the values in the hyperextension position (both the
HPVP and HPKP groups) at the three time points had significant differences $(P<0.01)$. The ODI scores in the NPKP, HPVP, and HPKP groups at the three timepoints had significant differences $(P<0.01)$. For the Cobb's angle and AR, all three groups (NPKP, HPVP, and HPKP) except the NPVP group showed Cobb's angle and anterior vertebral height recovery on POD2 $(P<0.01)$, and the reductions decreased at the one-year follow-up $(P<0.01)$, although they were partly maintained $(P<0.01)$. For the MR, all four groups showed a trend of recovery on POD2 $(P<0.01)$, but the reductions decreased at the one-year follow-up $(P<0.01)$, although they were partly maintained $(P<0.05)$.

The preoperative values of VAS, ODI, and the radiographic parameters showed no significant differences among the groups $(P>0.05)$. The VAS scores in the 
A
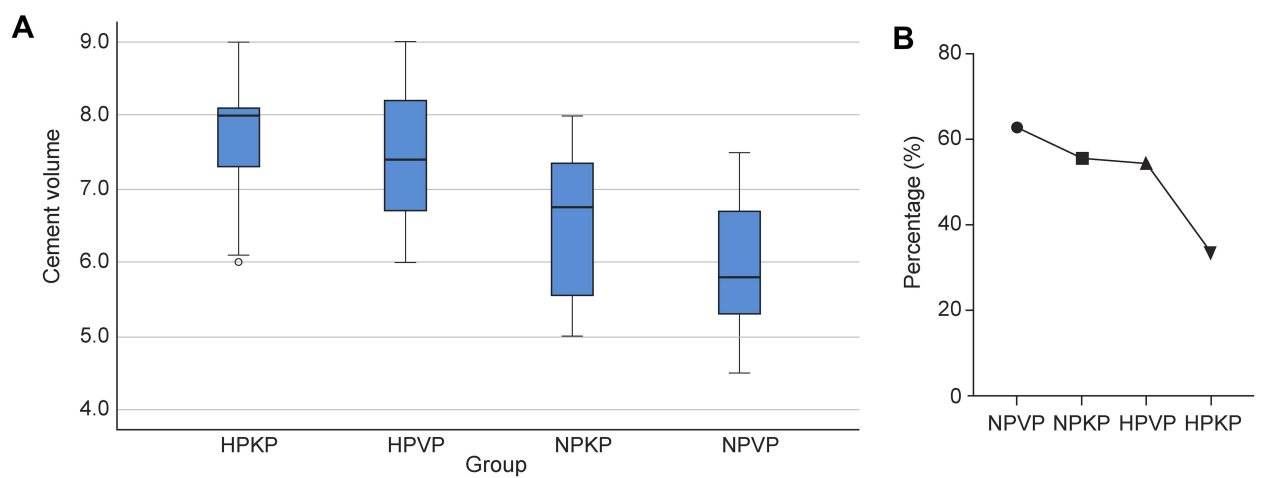

C

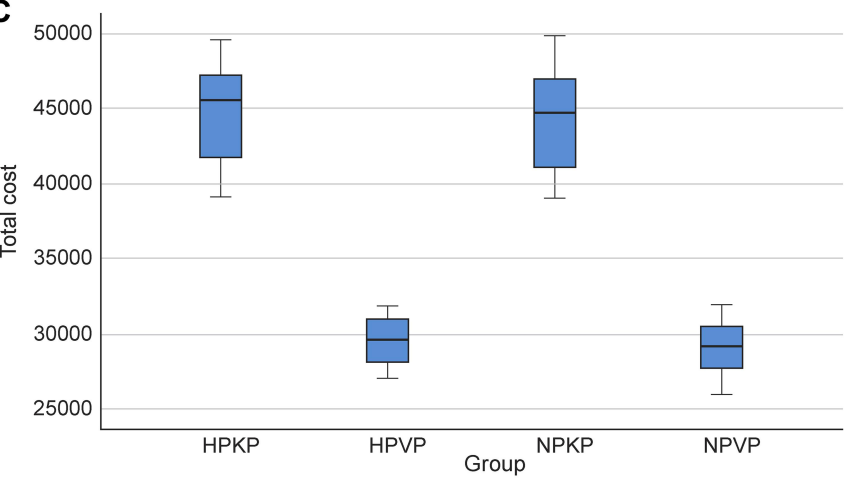

Figure 2 Box or line chart of cement volume injected, cement leakage rate and total cost. (A) Box chart of cement volume injected. The cement volumes injected were similar in the HPVP and HPKP groups $(P>0.05)$, were significantly higher than in the NPKP group $(P<0.0 \mathrm{I})$, and, further, were significantly higher than in the NPVP group $(P<0.0$ I). (B) Line chart of cement leakage rate. The leakage rate was lowest in the HPKP group, but was not significantly different from that in the NPKP group $(P>0.05)$. The leakage rate in the HPVP group was similar to that in the NPKP group $(P>0.05)$, but lower than that in the NPVP group, although the difference was not significant $(P>0.05)$. (C) Box chart of total cost. The total costs were similar in the NPVP and HPVP groups $(P>0.05)$, and in the NPKP and HPKP groups $(P>0.05)$. The cost to perform VP (both NPVP and HPVP) was significantly less $(P<0.0$ I) than that to perform KP (both NPKP and HPKP).

Abbreviations: NPKP, neutral position kyphoplasty; NPVP, neutral position vertebroplasty; HPKP, hyperextension position kyphoplasty; HPVP, hyperextension position vertebroplasty; VP, vertebroplasty; KP, kyphoplasty.

HPVP and HPKP groups were significantly lower than those in the NPVP and NPKP groups, both on POD2 and at the one-year follow-up $(P<0.01)$.

The ODI scores in the HPVP group were similar to those in the NPKP and HPKP groups $(P>0.05)$, but significantly lower than that in the NPVP group, on both POD2 and at the one-year follow-up $(P<0.01)$.

The values for Cobb's angle in the HPVP group were similar to those in the NPKP and HPKP groups $(P>0.05)$, but significantly smaller than that in the NPVP group, both on POD2 and at the one-year follow-up $(P<0.01)$. The values for both the AR and MR in the HPVP group were similar to those in the NPKP and HPKP groups $(P>0.05)$, but were significantly higher than those in the NPVP group, both on POD2 $(P<0.05)$ and at the one-year follow-up $(P<0.01)$.

\section{Discussion}

Pre- and postoperative analysis of VAS, ODI, Cobb's angle, AR, and MR indicated that NPVP, NPKP, HPVP, and HPKP were all effective for OVCF treatment. HPVP can achieve similar pain relief compared with the HPKP group, but lower pain scores compared with the NPVP and NPKP groups both on POD2 and at the one-year followup. HPVP can also achieve similar disability scores compared with the NPKP and HPKP groups, but better scores compared with NPVP, both on POD2 and at the one-year follow-up. Analysis of the Cobb's angle, AR, and MR suggested that HPVP achieved better kyphosis, anterior vertebral body height, and middle vertebral body height recovery on POD2, and better maintenance, than did NPVP; the values were similar to NPKP and HPKP at the one-year follow-up. The HPKP group had the lowest cement leakage rate. The rate in the HPVP group was similar to that in the NPKP group, and lower than that in the NPVP group. When considering only the total cost, HPVP was the most economically efficacious treatment for OVCF at the one-year follow-up.

Our literature review revealed that few publications compared VP to KP for treatment of OVCF. Cheng et $\mathrm{al}^{2}$ 


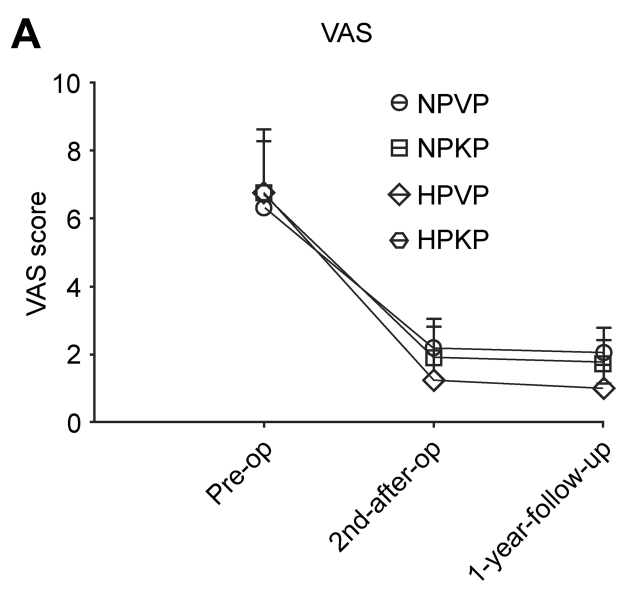

\section{B ODI}

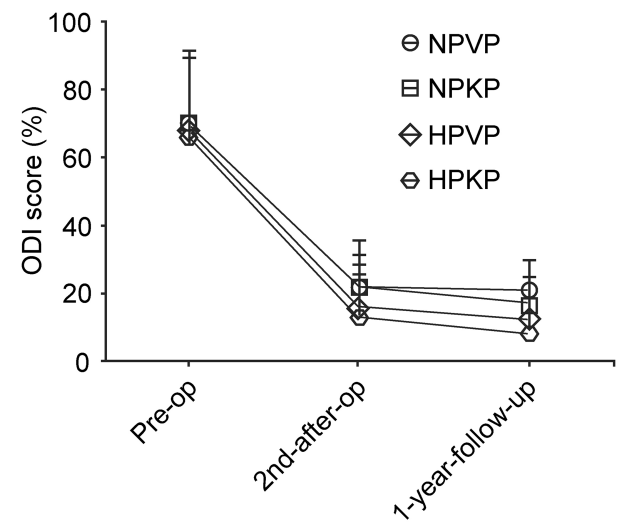

C

Cobb

D

\section{Anterior height}

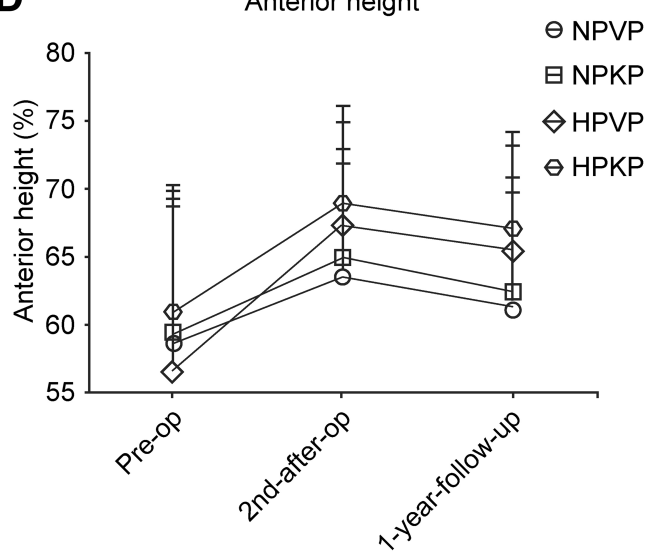

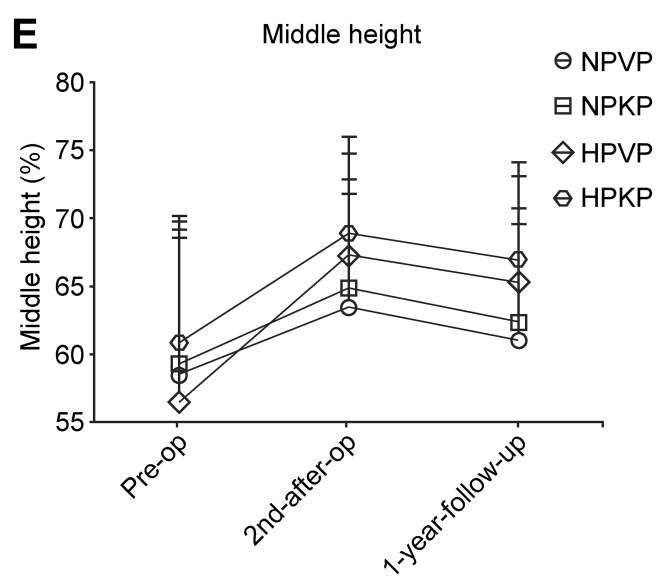

Figure 3 Line chart of VAS, ODI, and radiographic parameters. (A) Changing trend of VAS in the four groups. All groups showed downward trends at the three time points. Repeated measurements showed that the values at POD2 were significantly lower than those preoperatively $(P<0.01)$ but similar as those at the one-year follow-up $(P>0.05)$ in the neutral position (both NPVP and NPKP groups), while the values in the hyperextension position (both the HPVP and HPKP groups) at the three time points had significant differences $(P<0.01)$. (B) Changing trend of ODI in the four groups. All groups showed downward trends at the three timepoints. Repeated measurements showed that the value at POD2 was significantly lower than that preoperatively $(P<0.01)$, but were similar to that at the one-year follow-up $(P>0.05)$ in the NPVP group, while the values in the NPKP, HPVP, and HPKP groups at the three timepoints had significant differences $(P<0.01)$. (C) Changing trend of the Cobb's angle in the four groups. Repeated measurements showed that the three groups (NPKP, HPVP, and HPKP) other than the NPVP group experienced Cobb's angle recovery on POD2 ( $P<0.01)$ and that the reductions decreased at the one-year follow-up $(P<0.01)$, although they were partly maintained $(P<0.01)$. Although the Cobb's angle in the NPVP group showed recovery on POD2 $(P<0.01)$, the recovery was lost, and the values returned to the initial preoperative level at the one-year follow-up $(P<0.05)$. (D) Changing trend of AR in the four groups. Repeated measurements showed that the three groups (NPKP, HPVP, and HPKP) other than the NPVP group experienced AR recovery on POD2 ( $<<0.01$ ) and that the reductions decreased at the one-year follow-up $(P<0.01)$, although they were partly maintained $(P<0.01)$. Although AR in the NPVP group showed recovery on POD2 $(P<0.01)$, the recovery was lost, and the values returned to the initial preoperative level at the one-year follow-up $(P>0.05)$. (E) Changing trend of MR in the four groups. Repeated measurements revealed that all four groups showed a trend in MR towards recovery on POD2 $(P<0.01)$ but the reductions decreased at the one-year follow-up $(P<0.01)$, although they were partly maintained $(P<0.05)$.

Abbreviations: NPKP, neutral position kyphoplasty; NPVP, neutral position vertebroplasty; HPKP, hyperextension position kyphoplasty; HPVP, hyperextension position vertebroplasty; VAS, visual analog score; ODI, Oswestry Disability Index; AR, anterior vertebral body ratio; MR, middle vertebral body ratio. 
Table 2 Exact Values and Repeated Measurements of VAS, ODI and Radiographic Parameters

\begin{tabular}{|c|c|c|c|c|c|c|c|c|c|c|c|c|}
\hline & \multicolumn{4}{|c|}{ Preoperative } & \multicolumn{4}{|l|}{ POD2 } & \multicolumn{4}{|c|}{ One-Year Follow-Up } \\
\hline & NPVP & NPKP & HPVP & HPKP & NPVP & NPKP & HPVP & HPKP & NPVP & NPKP & HPVP & HPKP \\
\hline VAS & $\begin{array}{l}6.33 \\
\pm 1.96\end{array}$ & $\begin{array}{l}6.72 \\
\pm 1.91\end{array}$ & $\begin{array}{l}6.74 \\
\pm 1.92\end{array}$ & $\begin{array}{l}6.73 \\
\pm 1.84\end{array}$ & $\begin{array}{l}2.17 \\
\pm 0.90\end{array}$ & $\begin{array}{l}1.94 \\
\pm 0.86\end{array}$ & $\begin{array}{l}\text { I. } 28 \\
\pm 0.94^{\text {b,d }}\end{array}$ & $\begin{array}{l}\text { I. } 24 \\
\pm 0.87^{\text {b,d }}\end{array}$ & $\begin{array}{l}2.06 \\
\pm 0.76\end{array}$ & $\begin{array}{l}1.78 \\
\pm 0.64\end{array}$ & $\begin{array}{l}I .04 \\
\pm 0.72^{\mathrm{b}, \mathrm{d}}\end{array}$ & $\begin{array}{l}0.97 \\
\pm 0.73^{\mathrm{b}, \mathrm{d}}\end{array}$ \\
\hline $\begin{array}{l}\text { ODI } \\
\text { (\%) }\end{array}$ & $\begin{array}{l}69.40 \\
\pm 20.34\end{array}$ & $\begin{array}{l}70.13 \\
\pm 21.36\end{array}$ & $\begin{array}{l}68.72 \\
\pm 20.51\end{array}$ & $\begin{array}{l}65.94 \\
\pm 23.55\end{array}$ & $\begin{array}{l}21.91 \\
\pm 9.40\end{array}$ & $\begin{array}{l}21.70 \\
\pm 13.99\end{array}$ & $\begin{array}{l}16.2 \mid \\
\pm 12.42^{b}\end{array}$ & $\begin{array}{l}13.12 \\
\pm 12.50^{b, c}\end{array}$ & $\begin{array}{l}20.81 \\
\pm 9.09\end{array}$ & $\begin{array}{l}16.82 \\
\pm 8.13\end{array}$ & $\begin{array}{l}12.50 \\
\pm 9.42^{\mathrm{b}}\end{array}$ & $\begin{array}{l}8.33 \\
\pm 11.45^{\mathrm{bd}}\end{array}$ \\
\hline $\begin{array}{l}\text { Cobb } \\
\left({ }^{\circ}\right)\end{array}$ & $\begin{array}{l}11.94 \\
\pm 5.18\end{array}$ & $\begin{array}{l}12.11 \\
\pm 5.19\end{array}$ & $\begin{array}{l}12.90 \\
\pm 5.65\end{array}$ & $\begin{array}{l}12.27 \\
\pm 5.23\end{array}$ & $\begin{array}{l}10.69 \\
\pm 4.80\end{array}$ & $\begin{array}{l}9.53 \\
\pm 4.51\end{array}$ & $\begin{array}{l}7.67 \\
\pm 4.44^{\mathrm{b}}\end{array}$ & $\begin{array}{l}7.68 \\
\pm 4.53^{\mathrm{b}}\end{array}$ & $\begin{array}{l}11.90 \\
\pm 4.87\end{array}$ & $\begin{array}{l}10.48 \\
\pm 4.69\end{array}$ & $\begin{array}{l}8.39 \\
\pm 4.48^{\mathrm{b}}\end{array}$ & $\begin{array}{l}8.34 \\
\pm 4.55^{\mathrm{b}}\end{array}$ \\
\hline $\begin{array}{l}\text { AR } \\
(\%)\end{array}$ & $\begin{array}{l}72.49 \\
\pm 11.27\end{array}$ & $\begin{array}{l}71.00 \\
\pm 12.52\end{array}$ & $\begin{array}{l}69.55 \\
\pm \mid 3.71\end{array}$ & $\begin{array}{l}72.97 \\
\pm 11.23\end{array}$ & $\begin{array}{l}76.48 \\
\pm \mid 0.31\end{array}$ & $\begin{array}{l}78.24 \\
\pm 8.70\end{array}$ & $\begin{array}{l}81.35 \\
\pm 10.79^{b}\end{array}$ & $\begin{array}{l}83.33 \\
\pm 8.7 \mathrm{I}^{\mathrm{b}}\end{array}$ & $\begin{array}{l}74.12 \\
\pm 10.75\end{array}$ & $\begin{array}{l}76.73 \\
\pm 8.87\end{array}$ & $\begin{array}{l}79.8 \mathrm{I} \\
\pm 10.64^{\mathrm{b}}\end{array}$ & $\begin{array}{l}81.55 \\
\pm 8.70^{\mathrm{b}}\end{array}$ \\
\hline $\begin{array}{l}\text { MR } \\
\text { (\%) }\end{array}$ & $\begin{array}{l}58.54 \\
\pm 10.67\end{array}$ & $\begin{array}{l}59.26 \\
\pm 10.54\end{array}$ & $\begin{array}{l}56.48 \\
\pm 12.15\end{array}$ & $\begin{array}{r}60.87 \\
\pm 9.29\end{array}$ & $\begin{array}{r}63.39 \\
\pm 8.39\end{array}$ & $\begin{array}{l}64.90 \\
\pm 7.96\end{array}$ & $\begin{array}{l}67.27 \\
\pm 8.76^{\mathrm{a}}\end{array}$ & $\begin{array}{l}68.92 \\
\pm 5.87^{\mathrm{b}}\end{array}$ & $\begin{array}{l}61.12 \\
\pm 8.50\end{array}$ & $\begin{array}{r}62.33 \\
\pm 8.43\end{array}$ & $\begin{array}{l}65.34 \\
\pm 8.76^{\mathrm{b}}\end{array}$ & $\begin{array}{l}66.96 \\
\pm 6.12^{b}\end{array}$ \\
\hline
\end{tabular}

Notes: Values are expressed as mean \pm standard deviation. ${ }^{a} P<0.05$ compared with the value of NPVP group at the same time point, ${ }^{\text {ab }} P<0.0 \mathrm{I}$ compared with the value of NPVP group at the same time point, ${ }^{c} P<0.05$ compared with the value of NPKP group at the same time point, ${ }^{d} P<0.01$ compared with the value of NPKP group at the same time point.

Abbreviations: POD2, second-day post operation; VAS, visual analog scale score; ODI, Oswestry Disability Index; AR, ratio of anterior vertebral body; MR, ratio of middle vertebral body; NPVP, vertebroplasty in neutral position; NPKP, kyphoplasty in hyperextension position; HPVP, vertebroplasty in hyperextension position; HPKP, kyphoplasty in hyperextension position.

analyzed 338 patients and found no significant differences in the VAS and ODI in the VP and KP groups. Similarly, Wang et $\mathrm{al}^{23}$ performed a cohort study comparing VP and $\mathrm{KP}$ treatment of OVCF, and found no significant differences between the groups. A meta-analysis published in $2019^{6}$ considered the comparative efficacy of VP and KP on analgesia and disability. Our data showed that HPVP had comparable efficacy with NPKP on ODI, which supported this finding. There were fewer references comparing Cobb's angle, AR, and MR between VP and KP. Wang et $\mathrm{al}^{23}$ found that the use of KP to treat severe OVCF (compression ratio $>40 \%$ ) achieved significantly better anterior height and local kyphotic angle recovery than did VP, both on POD1 and at the final follow-up. However, in our cohort, there were no significant differences between the Cobb's angle and AR among the NPKP, HPVP, and HPKP groups, either on POD2 or at one year postoperatively. The explanation may be, in our experience, that the hyperextension position can achieve similar efficacy in reduction to that of balloon dilation. In the hyperextension position, further balloon inflation may reach alert pressures easily, and may fail to achieve further Cobb's angle and anterior vertebral height recovery.

Previous research has demonstrated that segmental kyphosis shortened the anterior column and increased the load on adjacent vertebral bodies, thereby heightening the risk of adjacent segment fractures. ${ }^{24,25}$ Thus, maximal kyphosis correction should be a target in the treatment of OVCF. In our study, all groups other than the NPVP group attained some degree of kyphosis correction at the oneyear follow-up. HPVP can achieve better Cobb's angle recovery than can NPVP, and was comparable to NPKP and HPKP. Some researchers have demonstrated that kyphosis can induce lower back pain. ${ }^{26,27}$ The VAS and ODI score achieved by HPVP was lower than that of NPVP, and appeared consistent with the Cobb's angle recovery, both on POD2 and at the one-year follow-up. This may be due to better kyphosis correction in the HPVP group. Similar results have been reported previously. ${ }^{12}$ Our results showed that AR and MR recovery was better in the HPVP than in the NPVP group, and was similar to that in the NPKP and HPKP groups, both on POD2 and at the one-year follow-up. This may be because when the patient was placed in the hyperextension position, the anterior vertebral body could recover under the stretch stress of the anterior longitudinal ligament. ${ }^{13}$ This mechanism does not exist in the middle of the vertebral body. However, the balloon can dilate the space between the superior and inferior endplates. Thus, theoretically, patients in whom KP was performed should have achieved better MR recovery. However, in our experience, the improvement in MR was not apparent in most patients after balloon inflation. This was because the MR had recovered to some extent in the hyperextension position; 
further balloon inflation may reach the alert pressure more easily before further MR recovery.

Cement leakage is one of the main complications in VP and KP. Our results showed that the percentage of patients with cement leakage in the HPVP group was similar to that in the NPVP and NPKP groups, but higher than that in the HPKP group. It should be noted that all the percentages appeared to be very high in our cohort, relative to other studies. Wang et al ${ }^{23}$ reported a $26.3 \%$ prevalence of cement leakage; however, the average cement volume they injected was $3.2 \pm 1.0 \mathrm{~mL}$. Our cement volumes were $6.02 \pm 0.85 \mathrm{~mL}$, $6.53 \pm 0.96 \mathrm{~mL}, 7.43 \pm 0.89 \mathrm{~mL}$, and $7.69 \pm 0.75 \mathrm{~mL}$ in the NPVP, NPKP, HPVP, and HPKP groups, respectively, which are markedly higher than those of Wang et al. ${ }^{23}$ Higher volumes were related to the surgical procedures we performed. The higher the volume of cement injected, the greater the ratio of leakage would be. Some researchers have reported that comparatively diffused pattern bone cement was superior to solid lump distribution pattern for OVCFs. ${ }^{28,29}$ Thus, we attempted to obtain diffused pattern bone cement in all cases to prevent further re-collapse and refracture. Sometimes, we stopped the injection when minor leakage was noticed from the anterior edge of the vertebral body, or the superior or inferior endplate, to achieve the diffused pattern of bone cement. This was the main reason for our comparatively high leakage rate.

China constitutes one-fifth of the global population, and the prevalence of osteoporosis has been rising over the past few decades in parallel with an aging population. ${ }^{15,16} \mathrm{OVCF}$ is the most common complication of osteoporosis, and leads to chronic back pain, reduced activity, depression, and even increased mortality. ${ }^{15}$ In China, between 2015 and 2017, nearly one-third of OVCF inpatients underwent VP or KP. The high cost of treating OVCF placed a high economic burden on both the healthcare system and patients. ${ }^{15}$ Thus, finding an economical and efficient method for treating OVCF is essential. According to our data, HPVP is nearly half the cost of NPKP and can achieve comparative kyphosis recovery and better analgesia, without increasing the operation time and rate of complications. The total cost savings are significant, based on the large population of China; therefore, HPVP is worth promoting vigorously for the treatment of OVCF.

This study has some limitations. It is a retrospective comparative study, and no method was used to ensure unbiased randomization of the four groups. Additionally, the patient sample size was small, and data on longer-term follow-up clinical outcomes were unclear, due to the finite follow-up duration. A prospective randomized controlled study with longer-term follow-up would better assess the clinical outcomes of HPVP for the treatment of OVCF.

\section{Conclusion}

HPVP can achieve better pain relief, and similar disability scores, and Cobb's angle, AR, and MR recovery, with a lower total cost, compared to NPKP. When considering only the total cost, HPVP was the most economically efficacious treatment for OVCF at the one-year follow-up.

\section{Acknowledgments}

The authors would like to thank Editage (www.editage.

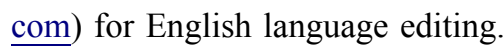

\section{Author Contributions}

All authors made substantial contributions to conception and design, acquisition of data, or analysis and interpretation of data; took part in drafting the article or revising it critically for important intellectual content; agreed to submit to the current journal; gave final approval of the version to be published; and agree to be accountable for all aspects of the work.

\section{Disclosure}

This study was supported by the Yantai Science and Technology Plan (2020YD039). The sponsors were not involved in any of the stages from study design to submission of the paper for publication.

The authors declare that they have no competing interests for this work.

\section{References}

1. Lamanna A, Maingard J, Kok HK, et al. Vertebroplasty for acute painful osteoporotic vertebral compression fractures: an update. J Med Imaging Radiat Oncol. 2019;63(6):779-785. doi:10.1111/ 1754-9485.12900

2. Cheng J, Muheremu A, Zeng X, Liu L, Liu Y, Chen Y. Percutaneous vertebroplasty vs balloon kyphoplasty in the treatment of newly onset osteoporotic vertebral compression fractures: a retrospective cohort study. Medicine (Baltimore). 2019;98(10):e14793. doi:10.1097/ MD.0000000000014793

3. Johnell O, Kanis JA. An estimate of the worldwide prevalence and disability associated with osteoporotic fractures. Osteoporos Int. 2006;17(12):1726-1733. doi:10.1007/s00198-006-0172-4

4. Goldstein CL, Chutkan NB, Choma TJ, Orr RD. Management of the elderly with vertebral compression fractures. Neurosurgery. 2015;77 (Suppl 4):S33-S45. doi:10.1227/NEU.0000000000000947

5. Clark W, Bird P, Gonski P, et al. Safety and efficacy of vertebroplasty for acute painful osteoporotic fractures (VAPOUR): a multicentre, randomised, double-blind, placebo-controlled trial. Lancet. 2016;388 (10052):1408-1416. doi:10.1016/S0140-6736(16)31341-1 
6. Zhu RS, Kan SL, Ning GZ, et al. Which is the best treatment of osteoporotic vertebral compression fractures: balloon kyphoplasty, percutaneous vertebroplasty, or non-surgical treatment? A Bayesian network meta-analysis. Osteoporos Int. 2019;30(2):287-298. doi:10.1007/s00198-018-4804-2

7. Lou S, Shi X, Zhang X, Lyu H, Li Z, Wang Y. Percutaneous vertebroplasty versus non-operative treatment for osteoporotic vertebral compression fractures: a meta-analysis of randomized controlled trials. Osteoporos Int. 2019;30(12):2369-2380. doi:10.1007/ s00198-019-05101-8

8. Diamond T, Clark W, Bird P, Gonski P, Barnes E, Gebski V. Early vertebroplasty within 3 weeks of fracture for acute painful vertebral osteoporotic fractures: subgroup analysis of the VAPOUR trial and review of the literature. Eur Spine J. 2020;29:1606-1613. doi:10.1007/s00586-020-06362-2

9. Kurra S, Metkar U, Lieberman IH, Lavelle WF. The effect of kyphoplasty on mortality in symptomatic vertebral compression fractures: a review. Int J Spine Surg. 2018;12(5):543-548. doi:10.14444/5066

10. Kim DH, Vaccaro AR. Osteoporotic compression fractures of the spine; current options and considerations for treatment. Spine J. 2006;6(5):479-487. doi:10.1016/j.spinee.2006.04.013

11. Schupfner R, Stoevelaar HJ, Blattert T, et al. Treatment of osteoporotic vertebral compression fractures: applicability of appropriateness criteria in clinical practice. Pain Physician. 2016;19(1):E113-E120.

12. Qi Y, Zeng Y, Jiang C, et al. Comparison of percutaneous kyphoplasty versus modified percutaneous kyphoplasty for treatment of osteoporotic vertebral compression fractures. World Neurosurg. 2019;122:e1020-e1027. doi:10.1016/j.wneu.2018.10.205

13. Ng JP, Cawley DT, Beecher SM, Baker JF, McCabe JP. The reverse thomas position for thoracolumbar fracture height restoration: relative contribution of patient positioning in percutaneous balloon kyphoplasty for acute vertebral compressions. Int J Spine Surg. 2016;10:21. doi:10.14444/3021

14. Lu J, Ren Z, Liu X, Xu Y-J, Liu Q. Osteoporotic fracture guidelines and medical education related to the clinical practices: a nationwide survey in China. Orthop Surg. 2019;11(4):569-577. doi:10.1111/ os. 12476

15. Yang D, Zhang Y, Ma X, Huo L, Li L, Gao Y. Resources utilisation and economic burden of percutaneous vertebroplasty or percutaneous kyphoplasty for treatment of osteoporotic vertebral compression fractures in China: a retrospective claim database study. $B M C$ Musculoskelet Disord. 2020;21(1):255. doi:10.1186/s12891-02003279-1

16. Yu F, Xia W. The epidemiology of osteoporosis, associated fragility fractures, and management gap in China. Arch Osteoporos. 2019;14 (1):32. doi:10.1007/s11657-018-0549-y

17. Zhang J, Fan Y, He X, et al. Is percutaneous kyphoplasty the better choice for minimally invasive treatment of neurologically intact osteoporotic Kümmell's disease? A comparison of two minimally invasive procedures. Int Orthop. 2018;42(6):1321-1326. doi:10.1007/s00264-018-3832-z
18. Chen GD, Lu Q, Wang GL, et al. Percutaneous kyphoplasty for Kümmell disease with severe spinal canal stenosis. Pain Physician. 2015;18(6):E1021-E1028.

19. Yang S, Chen C, Wang $\mathrm{H}$, Wu Z, Liu L. A systematic review of unilateral versus bilateral percutaneous vertebroplasty/percutaneous kyphoplasty for osteoporotic vertebral compression fractures. Acta Orthop Traumatol Turc. 2017;51(4):290-297. doi:10.1016/j. aott.2017.05.006

20. Chen W, Xie W, Xiao Z, Chen H, Jin D, Ding J. Incidence of cement leakage between unilateral and bilateral percutaneous vertebral augmentation for osteoporotic vertebral compression fractures: a meta-analysis of randomized controlled trials. World Neurosurg. 2019;122:342-348. doi:10.1016/j.wneu.2018.10.143

21. Wang H, Hu P, Wu D, Zhang N, Wu J, Xiang L. Age, gender, level and side differences in the anatomical distinctions of unilateral percutaneous kyphoplasty through the transverse process-pedicle approach. Pain Physician. 2019;22(2):E91-E96.

22. Li Y, Wang H, Cui W, et al. Clinical study of percutaneous vertebroplasty through extreme extrapedicular approach in the treatment of osteoporotic vertebral compression fracture. Zhongguo Xiu Fu Chong Jian Wai Ke Za Zhi. 2019;33(5):612-617.

23. Wang F, Wang LF, Miao DC, Dong Z, Chen Y. Which one is more effective for the treatment of very severe osteoporotic vertebral compression fractures: PVP or PKP? $J$ Pain Res. 2018;11:2625-2631. doi:10.2147/JPR.S179022

24. Minamide A, Maeda T, Yamada H, et al. Early versus delayed kyphoplasty for thoracolumbar osteoporotic vertebral fractures: the effect of timing on clinical and radiographic outcomes and subsequent compression fractures. Clin Neurol Neurosurg. 2018;173:176-181. doi:10.1016/j.clineuro.2018.07.019

25. Lindsay R, Silverman SL, Cooper C, et al. Risk of new vertebral fracture in the year following a fracture. JAMA. 2001;285 (3):320-323. doi:10.1001/jama.285.3.320

26. Kang CH, Shin MJ, Kim SM, Lee SH, Lee C-S. MRI of paraspinal muscles in lumbar degenerative kyphosis patients and control patients with chronic low back pain. Clin Radiol. 2007;62(5):479-486. doi:10.1016/j.crad.2006.12.002

27. Wilke HJ, Wolf S, Claes LE, Arand M, Wiesend A. Stability increase of the lumbar spine with different muscle groups. A biomechanical in vitro study. Spine (Phila Pa 1976). 1995;20(2):192-198. doi:10.1097/00007632-199501150-00011

28. Yu W, Xiao X, Zhang J, et al. Cement distribution patterns in osteoporotic vertebral compression fractures with intravertebral cleft: effect on therapeutic efficacy. World Neurosurg. 2019;123: e408-e415. doi:10.1016/j.wneu.2018.11.181

29. Yu WB, Jiang XB, Liang D, Xu WX, Ye LQ, Wang J. Risk factors and score for recollapse of the augmented vertebrae after percutaneous vertebroplasty in osteoporotic vertebral compression fractures. Osteoporos Int. 2019;30(2):423-430. doi:10.1007/s00198-018-4754-8
Journal of Pain Research

\section{Publish your work in this journal}

The Journal of Pain Research is an international, peer reviewed, open access, online journal that welcomes laboratory and clinical findings in the fields of pain research and the prevention and management of pain. Original research, reviews, symposium reports, hypothesis formation and commentaries are all considered for publication. The manuscript management system is completely online and includes a very quick and fair peer-review system, which is all easy to use. Visit http:// www.dovepress.com/testimonials.php to read real quotes from published authors. 